\title{
Spread Dynamics of Leucosis in Cattle in Livestock Farms of the Russian Federation for 2000-2018
}

\section{Vladimir Kuzmin¹, Mikhail Gulyukin², Aleksey Gulyukin², Artyom Metlin³, Gleb Prosvirnin ${ }^{1}$, Andrey Tsyganov ${ }^{1}$, Dmitriy Orekhov1, Svetlana Makavchik1, Ivan Khakhaev", and Dmitriy Evglevskiy ${ }^{4}$}

\author{
${ }^{1}$ Saint-Petersburg State Academy of Veterinary Medicine, St. Petersburg, Russia \\ ${ }^{2}$ Researchers from Federal State Budget Scientific Institution "Federal Scientific Centre VIEV" \\ (FSC VIEV), Moscow, Russia \\ ${ }^{3}$ All-Russian State Research Institute of Control, Standardization and Certification of Veterinary \\ Medicines, Moscow, Russia \\ ${ }^{4}$ Saint-Petersburg Electrotechnical University (ETU "LETI"), St. Petersburg, Russia \\ ${ }^{5}$ Kursk Research Institute of Agro-Industrial Production, Kursk, Russia
}

\section{Abstract}

Leucosis occupies a leading position in the modern nosological structure of cattle

Corresponding Author:

Vladimir Kuzmin

kuzmin@epizoo.ru

Received: 25 October 2019

Accepted: 15 November 2019

Published: 25 November 2019

Publishing services provided by

Knowledge E

(c) Vladimir Kuzmin et al. This article is distributed under the terms of the Creative Commons

Attribution License, which

permits unrestricted use and redistribution provided that the original author and source are credited.

Selection and Peer-review under the responsibility of the AgroSMART 2019 Conference Committee. infectious diseases. This is due to the high infection of livestock and large economic damage in affected farms [1-3]. Leucosis is a chronic tumor disease caused by an RNA-containing virus of the Retroviridae family. The disease is characterized by uncontrolled reproduction of immature hematopoietic cells $[4,5]$. The objective is to assess in dynamics the indicators of cattle infection with the leucosis virus and the incidence of leucosis in farms of all categories of the Russian Federation in the period of 2000--2018. The data of the analysis of the epizootic situation for leucosis in cattle in farms of all categories of the Russian Federation for 2000-2018 are presented. Over this period of time, the number of diagnostic serological studies in the immunodiffusion reaction increased 1.88 times in all subjects. According to the results of epizootological monitoring in farms of all categories of the Russian Federation, the rates of infection of the bovine leucosis virus decreased 1.89 times, the incidence rates decreased 2.02 times. At present, the epizootic situation has improved markedly, but so far there are problems with incomplete release of farms from leucosis in cattle. It is necessary to continue work on the elimination of this dangerous chronic disease in farms of all categories in the territory of the Russian Federation.

Keywords: leucosis in cattle, infection, incidence, serological research

\section{Introduction}

Enzootic leucosis in cattle is a malignant chronic disease of viral etiology that is either asymptomatic or characterized by lymphocytosis and malignant proliferation of hematopoietic andlymphoid cells in various organs [4]. Leucosis in cattle is one of 
For livestock breeding farms, leucosis in cattle causes significant economic damage, causing violation of breeding work and the raising of healthy pedigree young animals for sale, reduced productivity of dairy herds, utilization of carcasses of sick animals, restrictions on economic activity $[6,7]$.

Only the discovery of the leucosis in cattle virus and the further development of serological methods for the diagnosis of latent and overt infections made it possible to obtain accurate information about the spread of the disease in a particular area [8]. The causative agent is animals infected with leucosis in cattle virus and animals with blood changes typical for leucosis. It is the latter that pose a particular danger in the spread of leucosis infection. The joint keeping of sick and infected (virus carriers) animals leads to a constant increase in seropositive (in the immunodiffusion reaction) animals in the herd. The transmission of the leucosis in cattle virus to a susceptible livestock occurs with all the secreta and excreta when lymphocytes infected with the pathogen get into them. The interaction of the leucosis in cattle virus with susceptible livestock occurs at the level of the lymphocyte genetic apparatus, which determines the long-term (lifelong) preservation of the pathogen in the cattle $[5,6,9]$.

Leucosis in cattle is widespread in many countries on all continents, including the Russian Federation [7, 10--17].

The prevalence of leucosis in cattle in the Russian Federation is associated with the importation in 1941--1945 of a livestock of highly productive black-motley cattle carrying this disease to the territory of the country from East Prussia and the Baltic republics, and now -- with the import of pedigree cattle from seropositive animals conducted at the Researchers from Federal State Budget Scientific Institution "Federal Scientific Centre VIEV" (FSC VIEV) Moscow, Russia [15]. Phylogenetic analysis of the pathogen revealed the predominance of genotype IV "European cluster" out of 9 genetic variants of leucosis in cattle virus isolated in the world [18].

Bovine leucosis in the Russian Federation is epizootic and almost ubiquitous. Subjects free from bovine leucosis in the Russian Federation are considered 11 in 2014 and 14 in 2015. An alarming fact is the increase in the number of leucosis in cattle virus infected and sick animals amid a reduction in livestock numbers [18].

The objective is to assess in dynamics the indicators of cattle infection with the leucosis virus and the incidence of leucosis in farms of all categories of the Russian Federation in the period of 2000--018. 


\section{Methods and Equipment}

\subsection{Methods}

Sources of information for conducting epizootological studies are the source materials, allowing obtaining an approximate assessment of the situation of leucosis in cattle in a specific territory of the subject $[14,15,18]$. For epizootological analysis, statistical data of veterinary reporting, the results of diagnostic studies on leucosis of veterinary laboratories were used. The basis for the diagnosis of leucosis in cattle is the serological method of research -- the diffusion precipitation reaction (DPR), otherwise called the agar gel immunodiffusion reaction (IDR/RID). IDR is widely used in the Russian Federation in the elimination of leucosis as the main diagnostic method.

Diagnostic tests for leucosis in cattle by the serological method in the IDR and the hematological method are carried out in all laboratory departments of the constituent entities of the Russian Federation according to the "Guidelines for the diagnosis of bovine leucosis", approved by the Department of Veterinary Medicine of the Ministry of Agriculture of the Russian Federation, 2007 [19]. For IDR diagnostics, Russian diagnostic kits are used. From the number of animals that are positively responsive in IDR (infected with the bovine leucosis virus), patients with leucosis are identified using the hematological method.

The hematological research method consists in counting the number of leukocytes in a unit volume of blood $(1 \mu \mathrm{l})$ and a qualitative assessment of lymphoid elements -lymphocytes. Hematological examination is carried out on animals in the blood serum of which specific antibodies to leucosis in cattle virus were detected by serological method (IDR, ELISA). The count of leukocytes is carried out 1) using an electronic particle counter such as "Celloscope", "Culter", "Pikoskel" in accordance with the instructions (manuals) for their use or 2) in the counting chamber with the Goryaev's grid [19].

\section{Results}

The epizootological analysis and monitoring of leucosis in cattle virus infection revealed that, on average, $63.57 \%$ of animals were studied by the IDR method for the period of 2000--2018 in farms of all property categories of the Russian Federation (table 1) amid all cattle. The percentage of positive animals from the number of cattle examined in the IDR for this period of time averaged $8.31 \%$ (table 1 ) (with a maximum value of $11.03 \%$ in 2003 and a minimum value of $5.14 \%$ in 2018). 
The percentage of hematologically examined cattle in farms of all categories of property of the Russian Federation for the period 2000-2018 averaged $16.57 \%$ of the total animal population (table1).

The incidence rate of bovine leucosos in these farms over the same period of time (table 1) averaged $1.37 \%$, with a maximum value of $2.73 \%$ in 2003 and the minimum value of $0.94 \%$ in 2012 .

In Figure 1 the following is graphically presented: 1 ) an uptrend 1.88 -fold in the number of animals studied in IDR from the total number of cattle in 2018 compared to 2000; 2) a 1.35-fold downtrend in the number of hematologically examined animals from the total number of cattle in 2000 compared to 2018 ; 3) a 1.9-fold downtrend in the number of animals positive in IDR -- that is, infected -- on the number of animals examined in IDR; 4) a 2.01-fold downtrend in the number of hematologically positive animals -- that is, patients with leucosis from the number of hematologically examined animals.

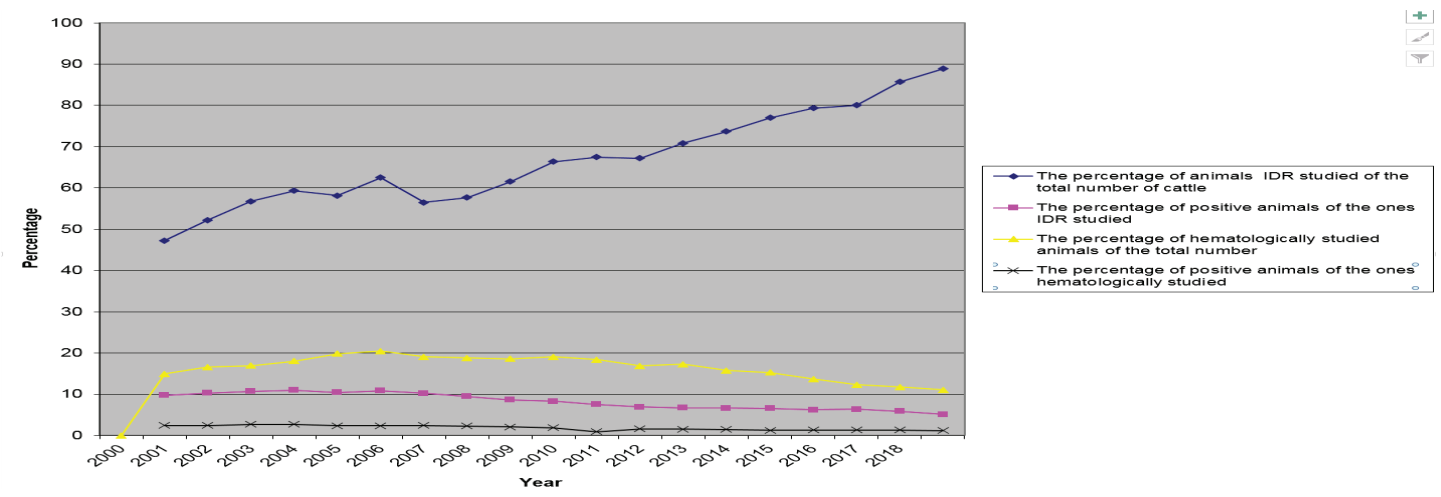

Figure 1: Annual monitoring of indicators of leucosis in cattle virus infection and leucosis incidence in farms of all categories of the Russian Federation for 2000--2018.

\section{Discussion}

In various regions and constituent entities of the Russian Federation, the level of diagnostic monitoring in the IDR of susceptible cattle was expanded [18]. The analysis of the epizootic situation of bovine leucosis in farms of all categories of the Russian Federation for 19 years revealed a 1.88 -fold increase in the coverage of leucosissusceptible livestock with diagnostic serological tests (RID).

According to the results of serological diagnostics (IDR), it was found that high rates of leucosis in cattle virus infection were observed for 6 years -- since 200 to 2006 . Virus carriers in this period were approximately at the same level and, respectively, amounted to $10.30 \%$ in 2001 and $10.22 \%$ in 2006 . The peak of the virus carrying level -- $11.03 \%$-was observed only in 2003 . These indicators of leucosis in cattle virus infection were 
TABLE 1: Indicators of leucosis virus infection and the incidence of leucosis in cattle in farms of all categories of the Russian Federation for 2000--2018.

\begin{tabular}{|c|c|c|c|c|}
\hline Year & $\begin{array}{l}\% \text { of the studied } \\
\text { animals in the IDR } \\
\text { of the total } \\
\text { number of cattle }\end{array}$ & $\begin{array}{c}\% \text { of positive } \\
\text { animals from the } \\
\text { number studied in } \\
\text { IDR }\end{array}$ & $\begin{array}{l}\text { \% of } \\
\text { hematologically } \\
\text { studied animals } \\
\text { from the total } \\
\text { number of cattle }\end{array}$ & $\begin{array}{c}\% \text { of positive } \\
\text { animals from the } \\
\text { hematologically } \\
\text { studied animals }\end{array}$ \\
\hline 2000 & 47.26 & 9.75 & 14.95 & 2.42 \\
\hline 2001 & 52.19 & 10.30 & 16.58 & 2.48 \\
\hline 2002 & 56.76 & 10.72 & 16.92 & 2.70 \\
\hline 2003 & 59.30 & 11.03 & 18.03 & 2.73 \\
\hline 2004 & 58.13 & 10.43 & 19.82 & 2.35 \\
\hline 2005 & 62.52 & 10.90 & 20.49 & 2.40 \\
\hline 2006 & 56.50 & 10.22 & 19.07 & 2.45 \\
\hline 2007 & 57.67 & 9.46 & 18.79 & 2.34 \\
\hline 2008 & 61.53 & 8.65 & 18.63 & 2.10 \\
\hline 2009 & 66.35 & 8.30 & 19.06 & 1.88 \\
\hline 2010 & 67.48 & 7.53 & 18.42 & 0.94 \\
\hline 2011 & 67.19 & 6.94 & 16.89 & 1.60 \\
\hline 2012 & 70.87 & 6.71 & 17.27 & 1.52 \\
\hline 2013 & 73.69 & 6.66 & 15.80 & 1.48 \\
\hline 2014 & 77.02 & 6.61 & 15.32 & 1.31 \\
\hline 2015 & 79.36 & 6.26 & 13.68 & 1.31 \\
\hline 2016 & 80.02 & 6.37 & 12.32 & 1.34 \\
\hline 2017 & 85.71 & 5.90 & 11.77 & 1.35 \\
\hline 2018 & 88.87 & 5.14 & 11.05 & 1.20 \\
\hline
\end{tabular}

detected in $59.30 \%$ of the studied animals in the IDR of the total number of cattle (table 1). Since 2007 (9.46\%), cattle leucosis virus infection rates gradually decreased and reached the minimum level of $5.14 \%$ by 2018 .

According to the results of hematological blood tests in 2003 a peak $(2.73 \%)$ in the incidence of cattle with leucosis was registered in farms of all categories of the Russian Federation (table 1). The disease was detected in $18.03 \%$ of hematologically examined animals from the entire livestock. Then the number of animals with leucosis amid the number of hematologically examined animals decreased from $2.35 \%$ in 2004 up to 0.94 \% in 2010. In 2011 the incidence of leucosis in cattle increased to $1.6 \%$ and gradually decreased to $1.2 \%$ in 2018 from the number of hematologically examined animals. 
A difficult epizootic situation has been recorded in leucosis in cattle in many regions and constituent entities of the Russian Federation for many years. The rather high level of infection of the leucosis in cattle virus and the incidence of leucosis led to the development of systems of anti-epizootic measures and targeted programs for the recovery of cattle from leucosis in specific territories and in farms of all categories of the Russian Federation [6].

In a retrospective aspect, over 19 years of observation of the epizootic process, it can be noted that at present, the rates of infection and the incidence of leucosis in cattle in farms of all categories of the Russian Federation have significantly decreased. This was the result of the country's system of anti-epizootic measures for the prevention and control of leucosis in cattle for many years [7, 8, 20, 21].

\section{Conclusion}

The recognition and establishment of the viral nature of leucosis in cattle has opened the main ways to infect animals, and the development and implementation of serological diagnostics (IDR/RID) in laboratory practice has made it possible to identify not only patients, but also animals infected with the leukemia virus.

The system of anti-epizootic measures for the recovery of infected herds from leucosis in cattle, used in livestock farms of the Russian Federation, is based on general provisions of directives taking into account regional conditions.

Relatively incomplete coverage by serological testing and insufficient production of diagnostic kits determine an incompletely reliable epizootic situation for leucosis in cattle in the reported data, which, in turn, inhibits wellness work on farms and hinders the study of epizootological monitoring in many subjects.

The data of the analysis of the epizootic situation for leucosis in cattle in farms of all categories of the Russian Federation for 2000--2018 are presented. Over this period of time, the number of diagnostic serological studies in the immunodiffusion reaction increased 1.88 times in all subjects. According to the results of epizootological monitoring in farms of all categories of the Russian Federation, the rates of infection of the leucosis in cattle virus decreased 1.89 times, the incidence rates decreased 2.02 times. At present, the epizootic situation has improved markedly, but so far there are problems with incomplete release of farms from leucosis in cattle. It is necessary to continue work on the elimination of this dangerous chronic disease in farms of all categories in the territory of the Russian Federation. 


\section{References}

[1] Borovoy, V. (2015). Problems in the prevention and elimination of bovine leucosis in the Russian Federation. Farm animals, no. 1, pp. 30--33.

[2] Stegniy, B.T., Shapovalova O.V., Gorbatenko S.K. et al. (2013). Modern aspects of bovine leucosis. Veterinary Medicine, no. 97, pp. 242--255.

[3] Loginov, S.I. (2015). Ecological and epizootological analysis of the total risk of bovine leucosis. Bulletin of the Novosibirsk State Agrarian University, no. 4(37), pp. 114--120.

[4] Syurin, V.N., Samuylenko, A.YA., Solovyov, B.V., Fomina, N.V. (2001). Bovine Leucosis. In: Animal Viral Diseases. Moscow, pp. 383--407.

[5] Nachmanson, V.M. (1986). Bovine Leucosis. Moscow, 103 p.

[6] Apal'kin, V.A., Gulyukin, M.I., Petrov, N.I. (2005). Bovine Leucosis. St. Petersburg, 105 p.

[7] Donnik, I.M., Dzhailidi G.A., Tikhonov S.V. (2013). Prevention of bovine leucosis in pedigree farms of the Krasnodar Territory. Veterinary Medicine of Kuban, no. 5, pp. 8--10.

[8] Simonyan, G.A. (2016). Methods for the diagnosis and control of the elimination of economic damage in bovine leucosis. Proceedings of the Veterinary Institute of Experimental Veterinary Medicine, vol. 79, pp. 267--275. Moscow.

[9] Morozova, O.V. (2015). The functional state of T-lymphocytes in the evaluation of cattle herds with leucosis. PhD dissertation thesis. Omsk, $137 \mathrm{p}$.

[10] Lee, E., Kim, E.J., Joung, H.K. et al. (2015). Sequencing and phylogenetic analysis of the gp51 gene from Korean bovine leukemia virus isolates. Virol. Journal, no. 12, p. 64.

[11] Ochirkhuu, N., Konnai, S., Odbileg, R. et al. (2016). Detection of bovine leukemia virus and identification of its genotype in Mongolian cattle. Arch Virol., no. 161, pp. 985-991.

[12] Sandev, N., Illieva, D., Rusenova, N. et al. (2015). Prevalence of enzootic BobivneLeukosis in Bulgaria. Bulletin UASVM Veterinary Medicine, no. 72, pp. 43-46.

[13] Fogel, L., Kozyrenko, O., Kuzmin, V., Dzhavadov, E., Danko, Y. (2019). Analytical review of current state the epizootic situation of catte leukemia in the Russian Federetion. Indo-American Journal of Pharmaceutical Sciences (IAJPS), no. 06(03), pp. 5289-5292.

[14] Lysov, A.V., Petropavlovskiy, M.V., Krivonogova, A.S., Donnik, I.M. (2017). The system of individual veterinary and zootechnical measures for the rehabilitation of 
dysfunctional farms from bovine leucosis on the example of the Tyumen region. Questions of normative-legal regulation in veterinary medicine, no. 3, pp. 40--43.

[15] Naymanov, A.Kh. Ovdiyenko, N.P., Tseluyeva, N.I. (2004). Clarification of the epizootic status of cattle herds in the farms of the Smolensk region. Veterinary pathology, no. $1 / 2$, pp. 167--170.

[16] Skhatum, A.K. (2002). Epizootology of bovine leukosis and improvement of the system of anti-leukemia measures in the farms of the Krasnodar Territory. PhD dissertation thesis. Krasnodar, $151 \mathrm{p}$.

[17] Glazunov, Yu.V., Kabitskaya, YA.A., Plotnikov, I.V. (2017). Comparative evaluation of methods of intravital diagnosis and epizootic situation in bovine leucosis in the Tyumen region. Bulletin of the agro-industrial complex of Stavropol: Stavropol State Agrarian University, no. 2(26), pp. 63--68.

[18] Kozyreva, N.G., Gulyukin, M.I. (2017). The spread of bovine leucosis and genetic variants of the pathogen on the territory of livestock farms of the Central Federal District of the Russian Federation. Veterinary medicine of Kuban, no. 6, pp. 4--9.

[19] Guidelines for the diagnosis of bovine leucosis. (2007).Approved by the Department of Veterinary of the Ministry of Agriculture of the Russian Federation,

[20] Novosel'tsev, G.G. (2013) Features of the manifestation of enzootic bovine leucosis and improvement of antiepizootic measures: PhD dissertation thesis. Stavropol, 128 p.

[21] Amirokov, M.A. (2011). Comprehensive assessment of factors affecting the manifestation and spread of bovine leucosis and the improvement of the system that ensures epizootic well-being. PhD dissertation thesis. Barnaul, $36 \mathrm{p}$. 